\author{
Thaíssa Tamarindo da Rocha Weishaupt Proni \\ Universidade Estadual de Campinas, Campinas, SP, Brasil
}

Marcelo Weishaupt Proni Universidade Estadual de Campinas, Campinas, SP, Brasil

\title{
Discriminação de gênero em grandes empresas no Brasil
}

\begin{abstract}
Resumo: O problema da discriminação de gênero no trabalho também se manifesta em grandes empresas. Em geral, os homens recebem salários maiores que as mulheres, mesmo que exerçam a mesma função. É mais difícil para as mulheres alcançar posição hierárquica elevada por causa do "teto de vidro". O combate à discriminação de gênero - propiciado pela evolução da legislação trabalhista e por políticas públicas - é essencial para valorizar a força de trabalho feminina, mas não é capaz de eliminar as diferenças em termos de ascensão na carreira e de remuneração entre homens e mulheres, mesmo em empresas líderes de mercado. As iniciativas de promoção da equidade de gênero no mundo corporativo, contempladas em programas de responsabilidade social empresarial, produzem avanços lentos e requerem uma mudança da cultura organizacional.
\end{abstract}

Palavras-chave: discriminação de gênero; legislação trabalhista; teto de vidro

\section{Introdução}

O papel da mulher na sociedade brasileira, de modo geral, tem sido ampliado à medida que vai sendo questionada a "divisão sexual do trabalho" (Helena HIRATA; Danièle KERGOAT, 2007). Atualmente, as mulheres estão presentes em quase todas as profissões, inclusive em atividades antes destinadas apenas aos homens, como na engenharia mecânica, no transporte público, na carreira militar, dentre outras. A imagem social da mulher que constrói uma carreira profissional passou a ser mais valorizada (Astrid Nilsson SGARBIERI, 2006). Além de superar a segregação ocupacional, um número crescente de mulheres vem conquistando maior respeito profissional e alcançando cargos de chefia e comando, embora os homens ainda predominem na diretoria das empresas e em funções gerenciais, principalmente no setor privado.

\section{(c) (7)}

Esta obra está sob licença Creative Commons. 
Apesar da nova imagem social e da legislação trabalhista em vigor, muitas mulheres continuam sofrendo discriminação no mercado de trabalho brasileiro, uma vez que algumas ocupações ainda são vistas como tipicamente masculinas ou femininas em razão da prevalência de uma cultura machista, herança de uma sociedade marcadamente patriarcal (Lia Zanotta MACHADO, 2000). E muitas mulheres são discriminadas devido à dificuldade de conciliar a atividade profissional com a vida familiar (Merike BLOFIELD; Juliana MARTíNEZ, 2014).

Na Constituição Federal de 1988 estão assegurados direitos iguais para homens e mulheres, com especial ênfase na esfera laboral. Desde então, foram criadas políticas públicas para combater a discriminação e evitar que a força de trabalho feminina fosse propositalmente segregada ou desqualificada (Lena LAVINAS, 1996). Todavia, boa parte das mulheres permaneceu submetida a uma dupla jornada de trabalho - em razão de serem vistas socialmente como responsáveis pelo cuidado de crianças, idosos e pessoas com deficiência. $E$, apesar das conquistas no plano legal e normativo, a discriminação de gênero continuou se manifestando de diferentes maneiras no Brasil (HIRATA, 2007).

Ao se examinar a divisão sexual do trabalho e a questão da discriminação, deve-se considerar a polarização existente no mercado de trabalho nacional, que se revela na segmentação dos postos de trabalho em termos de nível de produtividade e nível de remuneração. Acreditava-se que no polo onde as ocupações são mais qualificadas e os empregos são mais bem regulamentados havia condições mais favoráveis para combater a discriminação de gênero (Cristina BRUSCHINI, 2000). Embora a introdução de inovações tecnológicas e a adoção de novos métodos de organização do trabalho na década de 1990 tenham requerido um perfil de trabalhador instruído, polivalente e responsável, a maioria da força de trabalho feminina em empregos formais continuou a ser alocada em tarefas rotineiras e pouco qualificadas, muitas vezes terceirizadas (Magda de A. NEVES, 2000).

Apesar das melhorias expressivas no mercado de trabalho nacional, nos anos 2000 , e da adoção de programas voltados à igualdade de gênero, parcela expressiva das mulheres permaneceu inserida no polo marcado por trabalhos precários, geralmente em atividades de baixa produtividade, como os serviços pessoais e o trabalho doméstico (Marcia de Paula LEITE; Carlos SALAS, 2014). Por outro lado, mesmo a força de trabalho feminina que obteve emprego com a carteira assinada recebia, em geral, salários menores do que os homens, ainda que possuísse grau de instrução equivalente ou maior (Marcelo Weishaupt PRONI; Eugenia Troncoso LEONE, 2013).

Também no caso das mulheres que conseguem penetrar no mundo corporativo pode-se constatar a presença de mecanismos discriminatórios: dificilmente alcançam as posições hierárquicas mais elevadas numa grande empresa - fenômeno conhecido como "teto de vidro" (Andrea Valéria STEIL, 1997) -, pois tais cargos geralmente estão reservados aos homens. Este tem sido, aliás, um tema relevante para a política de gestão de pessoas em grandes empresas, que precisam demonstrar uma postura socialmente correta e de vanguarda.

O artigo tem dois objetivos. Primeiro: comprovar que o combate à discriminação de gênero propiciado pela evolução da legislação trabalhista (e por ações fiscalizadoras ou educativas das instituições públicas do trabalho) é fundamental para valorizar a força de trabalho feminina, mas não tem sido capaz de eliminar as diferenças em termos de ascensão na carreira e de remuneração entre homens e mulheres, em particular nas empresas de grande porte. Segundo: mostrar que há iniciativas de promoção da equidade de gênero no mundo corporativo, mas que os avanços são lentos, requerendo das grandes empresas uma mudança profunda da cultura organizacional. 


\section{A proteção legal às mulheres trabalhadoras no Brasil}

A valorização e a proteção ao trabalho da mulher no Brasil estão associadas com a evolução do Direito do Trabalho e à atuação das instituições públicas que deveriam assegurar sua efetividade, tais como o Ministério do Trabalho e Emprego, o Ministério Público do Trabalho e a Justiça do Trabalho (Alice Monteiro de BARROS, 1995; Léa Elisa Silingowsch CALIL, 2000).

Durante a "era Vargas", avançou a emancipação legal das mulheres e a proteção à maternidade, legitimou-se a preocupação com a igualdade de direitos trabalhistas para homens e mulheres, assim como se reforçou o combate à discriminação no emprego. ${ }^{1}$ Por sua vez, a reforma constitucional do "regime militar", em 1967, incluiu a proibição de que o empregador adote critério de admissão por motivo de sexo, cor da pele e estado civil, e assegurou o direito à aposentadoria para as mulheres após 30 anos de contribuição (35 anos para os homens). Finalmente, a promulgação da Constituição Cidadã de 1988 pautada na universalização dos direitos sociais, propiciou garantia legal de igualdade no trabalho e contribuiu para uma maior efetividade da atuação das mulheres como atores sociais. Deve-se ressaltar, também, que os direitos trabalhistas ficaram restritos àquelas que possuem o registro do emprego na carteira de trabalho.

A proteção constitucional à maternidade e a valorização do trabalho da mulher no capítulo dos direitos sociais expressam uma influência internacional no ordenamento jurídico nacional, em especial no que se refere aos direitos humanos e ao estatuto do trabalho, apontando um avanço civilizatório (Norberto BOBBIO, 2004). No Brasil, esses direitos só foram efetivados em 1988, quando o Estado Democrático de Direito se solidificou.

A harmonização do direito pátrio às convenções da Organização Internacional do Trabalho contribuiu para o enfrentamento de obstáculos enfrentados pela mulher, uma vez que a legislação brasileira recepcionou em seu ordenamento convenções importantes, como as convenções de número 100 e 111 , versando sobre igualdade de remuneração para homens e mulheres trabalhadoras e a igualdade de tratamento em matéria de emprego, respectivamente (Sergio Pinto MARTINS, 2009).

A legislação trabalhista passou a abarcar uma série de comandos relativos à igualdade entre os sexos e à proteção ao trabalho da mulher (Cristiane Maria Sbalqueiro LOPES, 2006). Tais comandos foram ampliados para a proteção às gestantes e lactantes, visando à saúde da trabalhadora e do recém-nascido. O fundamental é que a Constituição Federal de 1988 assegurou, em seu artigo $5^{\circ}$, I, a igualdade de direitos e obrigações entre homens e mulheres, proibindo diferença de salários, de exercício de funções e de critérios de admissão por motivos de sexo, estado civil, idade e cor (1988). Além disso, alongou a licença-maternidade de 90 para 120 dias, sem prejuízo do emprego e do salário, inclusive para as trabalhadoras domésticas, avulsas e rurais. ${ }^{2}$ Outra inovação expressiva no campo dos direitos sociais foi a garantia do emprego da gestante desde a confirmação da gravidez até cinco meses após o parto, vedando a sua dispensa neste período.

A regulamentação do trabalho feminino que passou a vigorar no País eliminou (no âmbito do Direito) qualquer prática discriminatória ou restritiva à inserção feminina no

1 Em 1934, a proteção à mulher empregada que precisa amamentar e cuidar do recém-nascido passou a fazer parte dos direitos sociais na Constituição Federal. Porém, a Consolidação das Leis do Trabalho (CLT) - em 1943 - manteve a participação econômica tutelada pelo pai ou pelo marido, a qual só foi abolida em 1962. ${ }^{2}$ Em 1994, a trabalhadora segurada em modalidade especial passou a ter direito ao salário-maternidade (valor equivalente a 1 salário mínimo), desde que comprovasse a atividade rural, ainda que de forma descontínua, nos doze meses anteriores ao início do benefício. Encontram-se excluídas as estagiárias e autônomas, embora sejam seguradas obrigatórias da Previdência Social (Thaíssa Tamarindo da Rocha Weishaupt PRONI, 2013). 
mercado de trabalho, congregando o espírito das normas universais, revogando da antiga CLT qualquer dispositivo em contrário. Dentre muitos outros avanços, foram retirados os artigos que autorizavam a interferência do marido no contrato de trabalho da mulher adulta (Lei 7.855/89).

Uma série de leis revogatórias e medidas harmonizadoras ao texto constitucional foi integrando a legislação trabalhista, aprimorando a proteção ao trabalho da mulher e promovendo a igualdade de tratamento. Por exemplo, a Lei 9.263/96 agravou os casos de indução dolosa à prática de esterilização cirúrgica, a Lei $9.799 / 99$ proibiu a revista íntima e a utilização de referências ou critérios fundados em sexo e a Lei 10.244/01 revogou o artigo 376 da CLT para permitir a realização de horas extras por mulheres. Foram eliminadas também as diferenças na licença-maternidade para a mãe adotante.

Em 2012, importante entendimento jurisprudencial do Tribunal Superior do Trabalho modificou a Súmula 244, item III, a qual passou a ter seguinte redação: "III - A empregada gestante tem direito à estabilidade provisória prevista no art. 10, inciso II, alínea 'b', do Ato das Disposições Constitucionais Transitórias, mesmo na hipótese de admissão mediante contrato por tempo determinado" (2012).

Outra conquista expressiva ocorreu com o incremento trazido pela Lei 11.770/2008, que instituiu a prorrogação facultativa da licença-maternidade de 120 para 180 dias, com contrapartida fiscal por meio do programa Empresa Cidadã, alterando a Lei 8.212/ 1991. Embora a lei não tenha alterado o texto constitucional do art. $7^{\circ}, \mathrm{XVIII},{ }^{3}$ significou um marco na rediscussão das condições instituídas para o gozo da licença-maternidade após a histórica modificação de 1988 (PRONI, 2013). Em complemento, a Lei 13.257/2016 ampliou, igualmente em caráter facultativo, a licença-paternidade de 5 para 20 dias, nas mesmas condições.

Em suma, a legislação pertinente ao trabalho da mulher se atualizou, ao menos em parte, para acompanhar algumas transformações econômicas e sociais no último quarto do século XX. Sob o olhar da Sociologia do Trabalho, constata-se uma mudança de paradigma diante das inovações tecnológicas e das novas formas de organização do trabalho industrial, antes sedimentado na mão de obra masculina. Mas, certamente, as disputas políticas também jogaram um peso relevante nessa trajetória, sendo essencial entender o papel dos movimentos feministas na conquista de novos direitos sociais (HIRATA; KERGOAT, 2007).

É relevante enfatizar que o Estado brasileiro, como ocorreu em outros países, sofreu forte pressão de organismos internacionais para que aprimorasse a legislação de combate à discriminação de gênero, mas tal influência não explica o salto na proteção constitucional oferecida especificamente no caso da licença-maternidade.

Por sua vez, o desenvolvimento econômico e a consolidação da democracia ajudam a viabilizar avanços significativos na área da proteção social, mas não explicam o estágio alcançado em cada país. Foi necessária a presença de forças políticas favoráveis para que a resistência empresarial fosse vencida e houvesse avanço significativo nessa direção.

De modo geral e bastante sucinto, foram essas as respostas e os enfrentamentos produzidos pelo Direito do Trabalho nesse campo de disputa política no Brasil. Frise-se que, no mundo corporativo, a proteção legal geralmente é cumprida integralmente, mas isso não impede a ocorrência da discriminação de gênero. Embora muitas grandes empresas ofereçam benefícios específicos para suas funcionárias e tenham ampliado a licençamaternidade para seis meses, o gap salarial em relação aos homens persiste, assim como

${ }^{3}$ Art. $7^{\circ}$ São direitos dos trabalhadores urbanos e rurais, além de outros que visem à melhoria de sua condição social: art. XVIII: licença à gestante, sem prejuízo do emprego e do salário, com a duração de cento e vinte dias.

4 Revista Estudos Feministas, Florianópolis, 26(1): e41780 
as menores chances para alcançar postos de comando. Para sustentar tal afirmação, convém analisar os dados empíricos disponíveis.

\section{A discriminação das mulheres em estabelecimentos de grande porte}

Na década de 1980, a porcentagem de mulheres com carteira de trabalho assinada era muito menor do que a dos homens. Desde então, isso tem mudado, ainda que lentamente. De acordo com os dados da Relação Anual de Informações Sociais (RAIS) do Ministério do Trabalho e Emprego, aumentou a inserção das mulheres no mercado de trabalho institucionalizado após a Constituição Federal de 1988. A participação feminina no total dos empregos formais aumentou de 33,9\%, em 1988, para 36,9\%, em 1994, e $39,1 \%$, em 1999. Na década seguinte houve uma desaceleração, mas a taxa seguiu aumentando: 40,0\% em 2004 e 41,4\% em 2009. Em 2015, a força de trabalho feminina correspondia a $43,7 \%$ dos empregos formais no País.

A desigualdade de gênero se expressa no salário médio contratual. A diferença entre a remuneração recebida pelos homens e a recebida pelas mulheres diminuiu levemente na década passada: em dezembro de 2003, o salário médio das mulheres correspondia a $80,3 \%$ do salário médio dos homens, enquanto em dezembro de 2009 essa proporção correspondia a $83,3 \%$. No final de 2015 , as mulheres ganhavam, em média, $16,1 \%$ menos do que os homens ( $R \$ 2.292,70$ contra R\$ 2.734,00). Frise-se, contudo, que o diferencial era ainda mais elevado nos estabelecimentos industriais (onde as mulheres ocupavam $30,6 \%$ dos postos de trabalho): elas recebiam apenas $66,1 \%$ da remuneração média dos homens em 2015.

As diferenças de salário por sexo são significativas nos mais variados tipos de postos de trabalho: cargos de direção, ocupações profissionais de nível superior, ocupações técnicas e de serviços administrativos, ocupações de prestação de serviços, vendas, trabalho manual na produção de bens e serviços de manutenção e reparação (LEONE, 2015). É importante ressaltar, porém, que a discriminação de gênero se traduz em maior desigualdade de remunerações entre homens e mulheres no caso dos empregados com nível superior de educação, entre os quais as mulheres têm maior participação e superam em número absoluto os homens (LEONE; Marilane Oliveira TEIXEIRA, 2013).

Também de acordo com a RAIS, as mulheres são maioria entre os empregados registrados que possuem escolaridade mais elevada (nível de ensino superior completo ou pós-graduação): 59,1\% em 2015. Entre esses empregados com escolaridade superior (que correspondem a $20 \%$ do total), o salário médio das mulheres continua bem inferior ao dos homens: R\$ 4.360,00 contra R\$ 7.004,70 (diploma de graduação); R\$ 5.991,20 contra R\$ 8.594,00 (mestrado); R\$ 9.190,10 contra R\$ 11.334,00 (doutorado). Ou seja, no segmento com maior grau de instrução, a remuneração média feminina corresponde a apenas $62,2 \%$ da remuneração média masculina se ambos possuem o diploma de graduação; $69,7 \%$ se ambos possuem o mestrado; e $81,1 \%$ se ambos possuem o doutorado. Continua a acentuada a discriminação de gênero entre profissionais que competem pelos melhores postos de trabalho.

Assim, ainda que a divisão sexual do trabalho profissional esteja se alterando e que mulheres ocupem profissões de alta qualificação e status social, a discriminação permanece gerando condições desiguais. Muitas mulheres enfrentam no mercado de trabalho barreiras invisíveis ("teto de vidro") que acarretam grande dificuldade em galgar postos destacados e de maior responsabilidade, apesar das conquistas históricas do movimento feminista. Tal dificuldade pode estar relacionada com a dupla jornada de trabalho e a necessidade de 
conciliação entre vida profissional e vida familiar.

O "teto de vidro" é mais comum em empresas de grande porte, que serão aqui definidas como as que possuem estabelecimentos com pelo menos 500 funcionários. ${ }^{4}$

Em dezembro de 2015 havia 48 milhões e 60 mil vínculos de emprego formal no Brasil, dos quais aproximadamente um terço em empresas de grande porte $(8,2 \% \mathrm{em}$ estabelecimentos com 500 a 999 funcionários e $25,7 \%$ em estabelecimentos com 1000 ou mais funcionários). A força de trabalho feminina correspondia a $49,1 \%$ do total $(43,9 \%$ e $50,8 \%$, respectivamente) (Tabela 1).

Tabela 1 - Proporção de mulheres entre os empregados formais em estabelecimentos de grande porte, segundo o grupo ocupacional. Brasil: 2015.

\begin{tabular}{|l|c|c|c|}
\hline Grande Grupo Ocupacional & $\begin{array}{c}\text { de } \mathbf{5 0 0} \\
\text { até } \mathbf{9 9 9} \\
\text { funcionários }\end{array}$ & $\begin{array}{c}\mathbf{1 0 0 0} \\
\text { ou mais } \\
\text { funcionários }\end{array}$ & $\begin{array}{c}\text { Total } \\
\text { (500 ou } \\
\text { mais) }\end{array}$ \\
\hline $\begin{array}{l}\text { Membros superiores do poder público e } \\
\text { dirigentes de organizaçôes de interesse público }\end{array}$ & 45,9 & 53,3 & 51,9 \\
\hline Profissionais das ciências e das artes & 60,0 & 64,8 & 63,9 \\
\hline Técnicos de nivel médio & 58,0 & 67,5 & 65,5 \\
\hline Trabalhadores de serviços administrativos & 56,9 & 61,1 & 60,1 \\
\hline Demais grupos ocupacionais & 30,2 & 32,0 & 31,5 \\
\hline Total & 43,9 & 50,8 & 49,1 \\
\hline
\end{tabular}

Fonte: MTE-RAIS 2015. Elaboração própria.

Apesar do equilíbrio na distribuição de homens e mulheres em estabelecimentos de grande porte, é possível constatar que as mulheres eram maioria entre profissionais das ciências e das artes $(63,9 \%)$, técnicos de nível médio $(65,5 \%)$ e trabalhadores de serviços administrativos $(60,1 \%)$, mas eram minoria entre trabalhadores da produção, de vendas e de outros grupos ocupacionais $(31,5 \%)$.

A desigualdade de remuneração contratual entre homens e mulheres em estabelecimentos de grande porte é bem nítida: no conjunto, as funcionárias do sexo feminino ganhavam 21,5\% menos que os empregados do sexo masculino em 2015 (Tabela 2). Nos grandes estabelecimentos com menos de mil funcionários, as mulheres tinham um salário equivalente a $76,6 \%$ do salário dos homens; nos estabelecimentos com mil ou mais funcionários, essa proporção era de $77,8 \%$.

Considerando o grupo ocupacional, o salário contratual médio das mulheres correspondia a $64,5 \%$ do salário médio dos homens entre os membros superiores do poder

\footnotetext{
${ }^{4}$ Uma empresa é considerada de "grande porte" em função de seu faturamento anual e do número de funcionários contratados. De acordo com o BNDES (2010), grande empresa é aquela que apresenta uma receita operacional bruta anual superior a R\$ 300 milhões. O jornal Valor Econômico e a revista Exame costumam divulgar o ranking das mil maiores empresas operando no Brasil, mas há um número bem maior de empreendimentos privados de grande porte. Para o IBGE (2012), grande empresa é aquela que possui pelo menos 250 empregados. Segundo esse critério, havia 12,7 mil estabelecimentos de grande porte no Brasil, em 2010, que empregavam mais de 13,2 milhões de pessoas. Por sua vez, algumas tipologias diferenciam a grande empresa industrial daquelas que atuam no setor terciário (comércio e serviços), estabelecendo o corte em 500 empregados e 100 empregados, respectivamente (SEBRAE, 2013).
}

6 Revista Estudos Feministas, Florianópolis, 26(1): e41780 
Tabela 2 - Razão entre a remuneração média de mulheres e de homens em estabelecimentos de grande porte, segundo o grupo ocupacional. Brasil: 2015.

\begin{tabular}{|l|c|c|c|}
\hline Grande Grupo Ocupacional & $\begin{array}{c}\text { de } \mathbf{5 0 0} \\
\text { até } \mathbf{9 9 9} \\
\text { funcionários }\end{array}$ & $\begin{array}{c}\mathbf{1 0 0 0} \\
\text { 0u mais } \\
\text { funcionários }\end{array}$ & $\begin{array}{c}\text { Total } \\
\text { (500 ou } \\
\text { mais) }\end{array}$ \\
\hline $\begin{array}{l}\text { Membros superiores do poder público e } \\
\text { dirigentes de organizações de interesse público }\end{array}$ & 0,589 & 0,664 & 0,645 \\
\hline Profissionais das ciências e das artes & 0,596 & 0,605 & 0,606 \\
\hline Técnicos de nivel médio & 0,598 & 0,684 & 0,674 \\
\hline Trabalhadores de serviços administrativos & 0,786 & 0,741 & 0,755 \\
\hline Demais grupos ocupacionais & 0,602 & 0,577 & 0,585 \\
\hline Total & 0,766 & 0,778 & 0,785 \\
\hline
\end{tabular}

Fonte: MTE-RAIS 2015. Elaboração própria.

público e dirigentes de organizações de interesse público, $60,6 \%$ entre os profissionais das ciências e das artes, $67,4 \%$ entre os técnicos de nível médio e $75,5 \%$ entre os trabalhadores de serviços administrativos. Por sua vez, no conjunto dos demais grupos ocupacionais (onde são minoria), essa proporção era ainda menor: $58,5 \%$.

Os diferenciais de remuneração média contratual não se explicam pelo tempo na empresa. É importante mencionar que, em dezembro de 2015, os funcionários em empresas de grande porte tinham, em média, 8 anos e dois meses no estabelecimento, mas essa média alcançava 8 anos e 5 meses para mulheres e 7 anos e 10 meses para homens. Nos estabelecimentos com 500 a 999 funcionários o tempo médio no emprego das mulheres era $13,4 \%$ maior do que o dos homens, enquanto nos estabelecimentos com 1000 ou mais funcionários essa diferença era menor (4,1\%).

É preciso esclarecer que os homens, em média, possuem uma jornada de trabalho contratual um pouco maior do que as mulheres. Em 2015, a força de trabalho feminina em grandes empresas tinha de cumprir uma jornada mínima de 36,7 horas semanais, contra 39,8 horas para a força de trabalho masculina (razão $=0,923$ ). Nos estabelecimentos com um quadro de funcionários entre 500 e 999 pessoas, essa média era de 38,5 horas para mulheres e 41,1 horas para homens (razão $=0,938$ ). Em empresas com um quadro de funcionários com pelo menos 1000 empregados, a jornada contratual média era um pouco menor: 36,3 horas para mulheres e 39,4 horas para homens (razão $=0,921$ ). É preciso, portanto, considerar esse aspecto ao analisar os diferenciais salariais.

Na Tabela 3 pode ser examinada a desigualdade entre homens e mulheres referente à remuneração horária em estabelecimentos de grande porte. Com essa ponderação, nota-se que as mulheres ganhavam, em média, $15 \%$ menos que os homens em 2015. Nos estabelecimentos com menos de mil funcionários, as mulheres tinham um salário-hora equivalente a $81,7 \%$ do imputado aos homens; nos estabelecimentos com mil ou mais funcionários, essa proporção era de $84,5 \%$. Mas, considerando o grupo ocupacional, a razão entre o salário-hora médio das mulheres e dos homens apresentava diferenciais maiores: 0,687 entre os membros superiores do poder público e dirigentes de organizações de interesse público, 0,640 entre os profissionais das ciências e das artes, 0,739 entre os técnicos de nível médio e 0,777 nos serviços administrativos. 
Tabela 3 - Razão entre o salário-hora médio de mulheres e de homens em estabelecimentos de grande porte, segundo o grupo ocupacional. Brasil: 2015.

\begin{tabular}{|l|c|c|c|}
\hline Grande Grupo Ocupacional & $\begin{array}{c}\text { de } \mathbf{5 0 0} \\
\text { até } \mathbf{9 9 9} \\
\text { funcionários }\end{array}$ & $\begin{array}{c}\mathbf{1 0 0 0} \\
\text { ou mais } \\
\text { funcionários }\end{array}$ & $\begin{array}{c}\text { Total } \\
\text { (500 ou } \\
\text { mais) }\end{array}$ \\
\hline $\begin{array}{l}\text { Membros superiores do poder público e } \\
\text { dirigentes de organizaçōes de interesse público }\end{array}$ & 0,612 & 0,709 & 0,687 \\
\hline Profissionais das ciências e das artes & 0,620 & 0,640 & 0,640 \\
\hline Técnicos de nível médio & 0,652 & 0,746 & 0,739 \\
\hline Trabalhadores de serviços administrativos & 0,804 & 0,763 & 0,777 \\
\hline Demais grupos ocupacionais & 0,817 & 0,845 & 0,850 \\
\hline Total & 0,612 & 0,709 & 0,687 \\
\hline
\end{tabular}

Fonte: MTE-RAIS 2015. Elaboração própria.

Focando a atenção nos funcionários que ocupavam posição de comando em grandes estabelecimentos do setor privado em 2015 (Tabela 4), nota-se que 45,7\% dos cargos eram ocupados por mulheres (num total de 270 mil vínculos), sendo importante esclarecer que $45,3 \%$ dessas mulheres pertenciam ao subgrupo dos gerentes de áreas de apoio e 30,6\% eram diretoras ou gerentes em empresas de serviços de saúde, de educação ou culturais. A participação feminina só era maior que a dos homens entre os diretores e gerentes em empresas de serviços de saúde, de educação ou culturais $(74,4 \%)$. Nos demais subgrupos selecionados elas eram minoria, em especial entre os diretores de produção e operações $(20,1 \%)$ e entre os gerentes de produção e operações $(30,1 \%)$, o que pode significar um preconceito contra a presença feminina nesses cargos em muitos segmentos do setor privado ou a existência do chamado "teto de vidro".

A Tabela 4 também permite visualizar que a participação feminina em funções de comando se altera de acordo com o porte do estabelecimento. Nas empresas de grande porte com menos de 1000 empregados a participação das mulheres em cargos de comando era de apenas $16,8 \%$ entre os diretores de produção e operações, $25,4 \%$ entre os gerentes de produção e operações, $34,8 \%$ entre os diretores gerais. Pode-se dizer que há uma chance um pouco maior de mulheres alcançarem cargos de comando no setor privado quando aumenta o tamanho do estabelecimento.

A diferença salarial entre homens e mulheres que ocupam cargos de comando em estabelecimentos de grande porte no setor privado é expressiva. Por exemplo, em dezembro de 2015, a remuneração contratual média dos homens atuando como gerentes de áreas de apoio era de $\mathrm{R} \$ 13.367,90$ e a das mulheres no mesmo subgrupo ocupacional era de R\$ 9.920,60. Por sua vez, entre os diretores de produção e operações o hiato era ainda maior: R\$ 22.238,80 contra R\$ 13.620,60. Tais diferenças não se explicam pelo número de horas contratuais: a jornada semanal de trabalho média entre os diretores de produção e operações era de 41,7 horas para os homens, contra 40,9horas para as mulheres; entre os gerentes de áreas de apoio essas médias eram muito próximas, 41,9 horas e 41,5 horas, respectivamente.

8 Revista Estudos Feministas, Florianópolis, 26(1): e41780 
Tabela 4 - Proporção de mulheres entre os empregados formais em cargo de comando em estabelecimentos de grande porte. Brasil: 2015.

\begin{tabular}{|l|c|c|c|}
\hline Subgrupo Ocupacional & $\begin{array}{c}\text { de } \mathbf{5 0 0} \\
\text { até } \mathbf{9 9 9} \\
\text { funcionários }\end{array}$ & $\begin{array}{c}\mathbf{1 0 0 0} \\
\mathbf{0 u} \text { mais } \\
\text { funcionários }\end{array}$ & $\begin{array}{c}\text { Total } \\
\text { (500 ou } \\
\text { mais) }\end{array}$ \\
\hline Diretores gerais & 34,8 & 46,5 & 42,4 \\
\hline Diretores de produção e operaçōes & 16,8 & 21,9 & 20,1 \\
\hline Diretores de áreas de apoio & 37,3 & 47,6 & 44,6 \\
\hline $\begin{array}{l}\text { Diretores e gerentes em empresas de serviços } \\
\text { de saúde, educaçào ou cultura }\end{array}$ & 71,3 & 75,2 & 74,4 \\
\hline Gerentes de produção e operações & 25,4 & 33,3 & 30,1 \\
\hline Gerentes de áreas de apoio & 39,2 & 40,7 & 40,1 \\
\hline Total & 40,1 & 48,5 & 45,7 \\
\hline
\end{tabular}

Fonte: MTE-RAIS 2015. Elaboração própria.

Considerando o salário-hora médio calculado para os subgrupos selecionados, nota-se que as mulheres em posição de comando recebiam o equivalente a $61,6 \%$ do salário-hora médio dos homens (Tabela 5). A desigualdade era maior entre os diretores gerais (razão $=0,385$ ) e menor entre os diretores e gerentes de empresas de serviços de saúde, educação e culturais (razão $=0,802$ ). Nota-se, também, que as mulheres gerentes de áreas de apoio tinham um salário-hora que correspondia, em média, a $74,8 \%$ do estimado para os homens no mesmo subgrupo, ao passo que a desproporção no caso de diretores de áreas de apoio era bem maior (44,8\%). A Tabela 5 evidencia algumas diferenças entre os estabelecimentos de grande porte com menos de mil funcionários e aqueles com mais de mil empregados, mas em ambos a desigualdade estava presente.

Tabela 5 - Razão entre o salário-hora médio de mulheres e de homens em cargo de comando em estabelecimentos de grande porte. Brasil: 2015.

\begin{tabular}{|l|c|c|c|}
\hline Subgrupo Ocupacional & $\begin{array}{c}\text { de } \mathbf{5 0 0} \\
\text { até } \mathbf{9 9 9} \\
\text { funcionários }\end{array}$ & $\begin{array}{c}\mathbf{1 0 0 0} \\
\text { ou mais } \\
\text { funcionários }\end{array}$ & $\begin{array}{c}\text { Total } \\
\text { (500 ou } \\
\text { mais) }\end{array}$ \\
\hline Diretores gerais & 0,333 & 0,413 & 0,385 \\
\hline Diretores de produção e operações & 0,577 & 0,619 & 0,625 \\
\hline Diretores de áreas de apoio & 0,461 & 0,461 & 0,448 \\
\hline $\begin{array}{l}\text { Diretores e gerentes em empresas de serviços } \\
\text { de saúde, educação ou cultura }\end{array}$ & 0,610 & 0,850 & 0,802 \\
\hline Gerentes de produção e operaç̄̃es & 0,621 & 0,542 & 0,578 \\
\hline Gerentes de áreas de apoio & 0,743 & 0,748 & 0,748 \\
\hline Total & 0,617 & 0,610 & 0,616 \\
\hline
\end{tabular}

Fonte: MTE-RAIS 2015. Elaboração própria. 
Portanto, pode-se inferir que a discriminação de gênero continua sendo um problema para muitas mulheres que ocupam cargos de comando em estabelecimentos de grande porte no Brasil. A seguir, será examinada a situação em grandes empresas que exercem liderança nos respectivos mercados e seu compromisso com a equidade.

\section{A promoção da igualdade de gênero em grandes empresas}

À medida que o Direito do Trabalho evoluiu da proteção à mulher para a garantia de tratamento igual no ambiente de trabalho (Denise Pasello Valente NOVAIS, 2005), pari passu, as instituições públicas de defesa de direitos - como o Ministério Público do Trabalho e a Justiça do Trabalho - passaram a aplicar maior rigor na investigação e julgamento dos processos relativos à matéria. Em paralelo, o Governo Federal passou a adotar programas de promoção da equidade que foram reforçados com a criação da Secretaria de Políticas para as Mulheres (SPM). Foco especial foi colocado sobre a administração pública e as grandes corporações, que deviam demonstrar que era possível coibir a ocorrência de qualquer tipo de discriminação de gênero. ${ }^{5}$

Diante da repercussão jurídica e social da matéria relativa à equidade entre homens e mulheres, do aumento significativo de processos judiciais denunciando abusos, assédios e desigualdades de remuneração, da pressão exercida por instituições governamentais, da constante veiculação do tema na mídia e da militância de entidades sindicais, começou a se processar uma mudança cultural no mundo corporativo. Simultaneamente, à medida que a imagem social das grandes corporações passou a ser fundamental na sua estratégia de marketing, tornou-se necessário demonstrar uma postura "politicamente correta" perante acionistas e consumidores. Assim, em variados setores de atividade, as empresas líderes incluíram a valorização da diversidade e a promoção da equidade em seus programas de "responsabilidade social empresarial"’ (OBSERVATÓRIO SOCIAL, 2004; INSTITUTO ETHOS, 2007).

No início dos anos 2000 , enquanto se difundia no País um modelo mais abrangente de responsabilidade social corporativa, que incluía uma nova relação entre a empresa e seus funcionários, foi se modificando a postura sindical em relação às questões de gênero (considerando que se tratava de um meio predominantemente masculino). Os sindicatos mais combativos intensificaram a exigência de cumprimento do código de conduta nas empresas, estimulando seus filiados a denunciar casos de discriminação (OBSERVATÓRIO SOCIAL, 2004).

De acordo com o Perfil social, racial e de gênero das 500 maiores empresas do Brasil e suas ações afirmativas (INSTITUTO ETHOS, 2015), tem havido avanços significativos, mas permanece a sub-representação de mulheres em cargos de comando. Entre 2003 e 2015 aumentou a porcentagem de mulheres desempenhando funções executivas (de $9 \%$ para $13,6 \%$ ), funções gerenciais (de $18 \%$ para $31,3 \%$ ) e funções de supervisão (de $28 \%$ para $38,8 \%$ ), mas a grande maioria desses cargos ainda permanece ocupada por homens.

${ }^{5}$ O Programa Pró-Equidade de Gênero e Raça, criado em 2005, buscou a adesão de empresas que prezam pela promoção de igualdade entre mulheres e homens no trabalho. O programa concede o Selo PróEquidade de Raça e Gênero para empresas públicas e privadas. Em 2015, as 68 organizações inscritas no programa empregavam cerca de 1 milhão de trabalhadores no País.

${ }^{6}$ As grandes empresas podem contribuir de várias formas para o desenvolvimento social e devem prestar contas de suas atividades enquanto agentes sociais. Além de pagar corretamente os impostos, garantir a qualidade dos produtos e serviços oferecidos, gerar empregos decentes e zelar pela segurança dos trabalhadores, as suas responsabilidades sociais incluem a preservação do meio ambiente, o combate a qualquer tipo de discriminação e outras que não são exigidas por lei, como a contribuição para a educação profissional continuada e o apoio a projetos comunitários (Anacleto Laurino PINTO; Maisa de Souza RIBEIRO, 2004). 
Por sua vez, manteve-se a participação feminina em funções administrativas ou operacionais (de $35 \%$ para $35,5 \%$ ). Chama atenção o "afunilamento hierárquico", isto é, menor inclusão de mulheres à medida que aumentam as atribuições de comando (INSTITUTO ETHOS, 2015).

Ressalte-se que, em 2015 , apenas $28,2 \%$ dentre as 500 maiores empresas operando no Brasil (das quais $60 \%$ tinham mais de mil funcionários) adotavam alguma política para promover a igualdade de oportunidades para homens e mulheres, tais como: programa especial para contratação de mulheres, metas de participação feminina em cargos de direção e gerência, qualificação para exercer cargos de direção e gerência, redução da desigualdade salarial e conciliação entre trabalho e família. Em relação à presença de mulheres em níveis hierárquicos, $35,1 \%$ das empresas tinham medidas destinadas à gerência e $31,6 \%$ para o quadro executivo, mas parcela bem menor tinha uma política perene e com metas definidas para esses cargos (13,7\% e 12\%, respectivamente) (INSTITUTO ETHOS, 2015).

As razões apontadas pelas empresas pesquisadas para a baixa presença de mulheres em cargos diretivos e gerenciais eram as seguintes: falta de experiência na empresa para lidar com o assunto $(36,9 \%)$, falta de qualificação profissional para os cargos $(28,9 \%)$ e falta de interesse das próprias mulheres por cargos de maior responsabilidade $(34,2 \%)$ (INSTITUTO ETHOS, 2015).

A fim de compreender melhor como a questão de gênero tem sido tratada no meio corporativo, focando os avanços e dificuldades da promoção da equidade de gênero em grandes empresas que exercem papel de liderança no País, pode-se tomar como referência um grupo pequeno de corporações selecionadas.

\subsection{Esclarecimentos metodológicos}

Para a seleção das empresas analisadas foram usados dois critérios: a) ser uma companhia de capital aberto líder de mercado e estar entre as marcas mais valiosas no país; b) ter uma política específica para gênero na área de gestão de pessoas, com compromisso de elevar a participação de mulheres em posições de comando. Foram

Quadro 1 - Participação feminina em grandes empresas selecionadas

\begin{tabular}{|l|c|c|c|c|}
\hline Companhia & Ano & $\begin{array}{c}\text { Mulheres no total } \\
\text { dos empregados }\end{array}$ & $\begin{array}{c}\text { Mulheres em cargos } \\
\text { de gerência }\end{array}$ & $\begin{array}{c}\text { Mulheres em eargos } \\
\text { de direça }\end{array}$ \\
\hline Natura & 2015 & $58,0 \%$ & $55,6 \%$ & $33,3 \%$ \\
\hline Magazine Luiza & 2015 & $50,9 \%$ & $26,1 \%$ & $22,2 \%$ \\
\hline Banco do Brasil & 2015 & $41,6 \%$ & $35,2 \%$ & $5,6 \%$ \\
\hline Unilever & 2013 & $29,2 \%$ & $50,4 \%$ & $37,2 \%$ \\
\hline Nestlé & 2015 & $25,9 \%$ & $32,5 \%$ & $23,1 \%$ \\
\hline Petrobras & 2014 & $15,8 \%$ & $15,2 \%$ & $10,0 \%$ \\
\hline Coca-Cola & 2013 & $12,1 \%$ & $24,0 \%$ & $11,1 \%$ \\
\hline Volkswagen & 2014 & $6,4 \%$ & - & $8,9 \%$ \\
\hline
\end{tabular}

${ }^{7}$ A Nestlé foi considerada a marca mais confiável no País, segundo a pesquisa "Marcas de Confiança 2015" (IBOPE, 2015). As outras sete também figuram na lista. Os dados da $14^{a}$ edição da pesquisa, que é patrocinada pela Revista Seleções e realizada pelo lbope Inteligência, estão disponíveis em: http://mais.selecoes.com.br/ marcas_2015a/valor.html. 
selecionadas oito empresas líderes (de diferentes setores de atividade), sendo quatro multinacionais e quatro nacionais (duas estatais), a saber: Banco do Brasil, Coca-Cola, Magazine Luiza, Natura, Nestlé, Petrobras, Unilever e Volkswagen (Quadro 1). Todas se esforçam para manter uma imagem pública de confiabilidade e idoneidade. ${ }^{7}$

Foram analisados os relatórios anuais de sustentabilidade ou transparência corporativa divulgados por essas grandes empresas, os quais detalham (para os acionistas e o público em geral) os diversos programas e ações de responsabilidade social adotados no ano de referência $(2013,2014$ ou 2015).

Foram destacados quatro aspectos principais: a) participação feminina no total de empregados e em cargos de comando; b) relevância que os relatórios atribuem aos programas referentes à igualdade de gênero no âmbito das políticas de gestão de pessoas; c) consistência e abrangência dos programas apresentados (para identificar se o tema gênero é abordado de uma maneira superficial como estratégia de marketing ou se há realmente ações perenes e bem estruturadas); d) explicação oferecida pela própria companhia para justificar a baixa presença de mulheres em cargos de comando e a desigualdade de remuneração e de oportunidade de ascensão na empresa.

\subsection{Principais resultados}

Em relação à participação feminina no total de empregados e em cargos de comando, as empresas selecionadas ilustram a diversidade de situações existentes.

A participação feminina no total dos funcionários de cada empresa varia de acordo com o setor de atividade e a cultura organizacional: é expressiva na Natura (indústria de cosméticos) e no Magazine Luiza (comércio varejista), mas é minoritária na Volkswagen (indústria automobilística), na Coca-Cola (indústria de bebidas), na Petrobras (extração de petróleo e produção de combustíveis), na Nestlé (indústria de alimentos) e na Unilever (indústria de alimentos, produtos de limpeza doméstica e higiene pessoal). No Banco do Brasil (serviços financeiros) a participação feminina é relativamente alta, mas a participação masculina continua sendo majoritária.

A informação sobre a proporção de mulheres que ocupa posição de comando não é divulgada de maneira homogênea nos relatórios corporativos, por isso as porcentagens relativas às mulheres em cargos de gerência e em cargos de direção podem não ser rigorosamente comparáveis. De qualquer modo, o Quadro 1 permite evidenciar que, mesmo nas empresas em que as mulheres são maioria, há predominância dos homens nos postos de maior responsabilidade, remuneração e poder: na Natura apenas um terço dos cargos diretivos é ocupado por mulheres; no Magazine Luiza, pouco mais de um quinto. Por sua vez, na Coca-Cola, na Petrobras e na Volkswagen as mulheres ocupam apenas um em cada dez cargos de direção. Ressalte-se, ainda, que no Banco do Brasil a presença de mulheres na diretoria é bem desproporcional.

Para analisar a relevância, a consistência e as dificuldades dos programas de igualdade de gênero, convém examinar cada empresa separadamente.

A Natura tem sido considerada uma das empresas de "melhor reputação" no País, o que inclui a forma como cuida de suas equipes (conforme ranking divulgado pela Exame) (Daniela BARBOSA e Luísa MELO, 2014). A empresa tem feito esforços no sentido de aprimorar a gestão de pessoas e a cultura organizacional para responder às tendências globais observadas na forma como as pessoas se relacionam no mundo do trabalho, o que envolve questões complexas como flexibilidade, colaboração, diversidade e convivência de gerações. O Relatório Anual Natura 2015 é bastante detalhado em relação aos "colaboradores". A empresa possuía 5.151 funcionários no Brasil em 2015 com maior 
participação feminina do que masculina ( $58 \%$ contra $42 \%$ ). As mulheres eram maioria inclusive nos cargos de gerência (56\% contra $44 \%$ ). Mas eram minoria nos cargos de executivos (diretoria e acima), ainda que a porcentagem tenha aumentado entre 2012 e 2015 (26\% para 33\%). Apesar do compromisso com a promoção da igualdade de gênero, a remuneração média das mulheres diferia da dos homens: as empregadas em funções operacionais ganhavam $23 \%$ menos ( $R \$ 1.823,00$ contra R\$ $2.381,00$ ); em funções administrativas, ganhavam $20 \%$ mais ( $R \$ 8.256,00$ contra $R \$ 6.880,00$ ); nos cargos de gerência, $4 \%$ menos ( $R \$ 16.998,00$ contra $R \$ 17.631,00$ ); e nos cargos de diretoria, as mulheres recebiam $15 \%$ menos que os homens ( $R \$ 46.655,00$ contra $R \$ 54.843,00$ ) (NATURA, 2015).

O Magazine Luiza, que tem na presidência uma mulher, ${ }^{8}$ tem sido classificado entre as "dez melhores empresas para trabalhar no Brasil" (ranking do Great Place to Work Institute) (Mauro SILVEIRA, 2015). ${ }^{9}$ No Relatório Anual e de Sustentabilidade 2015 , é destacada a importância dos "colaboradores" (responsáveis pela força e vitalidade da organização) e é ressaltada a inclusão de pessoas com deficiência, mas não é mencionado um programa específico para a promoção de igualdade de gênero e não há informação sobre diferenças de remuneração entre homens e mulheres. Em 2015 o Magazine Luiza contava com 21.745 funcionários, sendo $51 \%$ mulheres. Houve redução de $12 \%$ no total de empregados (em relação a 2014), com taxa de desligamento maior para homens (43\%) do que para mulheres $(37,5 \%)$. Entre os que tinham cargo de chefia/coordenação, $67 \%$ eram mulheres, mas entre os gerentes apenas $26 \%$ eram mulheres. Entre os membros da diretoria, 21 eram homens e apenas 6 mulheres (22\%), e no conselho diretivo havia 5 homens e 2 mulheres $(29 \%)$ (MAGAZINE LUIZA, 2015).

O Banco do Brasil era classificado entre as melhores empresas para trabalhar (GUIA 2015; TOP, 2015) e era reconhecido como líder em gestão de pessoas ${ }^{10}$. Em 2010, aderiu aos Princípios de Empoderamento das Mulheres (ONU) e ao Programa Pró-Equidade de Gênero e Raça (SPM). Nos anos seguintes, o Banco do Brasil implantou um conjunto de ações para afirmar a diversidade como um valor presente na cultura organizacional, tais como a seleção externa com recortes de gênero e etnia, o aprimoramento da ação afirmativa de gênero no programa de ascensão profissional nas agências, o maior apoio a funcionárias gestantes e a melhoria dos benefícios concedidos para mães solteiras (ou em relação homoafetiva). Em 2015, foi lançado o curso "Equidade de gênero: uma questão cultural?", cujo objetivo era capacitar os funcionários para que adotassem ações que promovam o respeito às mulheres e à equidade de gênero na rotina de trabalho. Porém, a política nessa área mudou bastante após o Conselho de Administração extinguir a Vice-Presidência de Gestão de Pessoas em abril 2015.

O Relatório Anual 2015 do Banco do Brasil informa que havia 109.227 funcionários em 2015, com participação feminina de 41,6\%. Contudo, os cargos de liderança permaneciam reservados para os homens $(35 \%$ dos gerentes e apenas $6 \%$ dos diretores e conselheiros eram mulheres). E não havia igualdade de gênero em termos de remuneração média mensal. Embora nas funções técnicas e operacionais fosse pequena a diferença salarial entre homens e mulheres, havia um diferencial significativo quando considerada a

\footnotetext{
${ }^{8}$ Luiza Helena Trajano ocupava a segunda colocação no ranking da Carta Capital dos líderes empresariais "mais admirados" em 2015 (Paulo SECCHES, 2015)

'Os dados, embora retirados de Silveira (2015), estão disponíveis no site do Great Place to Work Brasil: http:/ /www.greatplacetowork.com.br/ranking/ranking-melhores-empresas-para-trabalhar.htm.

${ }^{10} \mathrm{~A}$ classificação completa está disponível no site do Top Employers Institute: https://www.top-employers.com/ pt-BR/certificados-top-employers/.
} 
função gerencial (em 2015, a remuneração média feminina correspondia a $83 \%$ da remuneração masculina) (BANCO DO BRASIL, 2015).

O Relatório de Sustentabilidade 2013 da Unilever Brasil compreende o cuidado com o meio ambiente, processos produtivos, gestão de pessoas e valorização das marcas que produz e comercializa. No conjunto dos 13.035 funcionários, a participação feminina era de $29 \%$, havendo presença majoritária dos homens em atividades administrativas e nas linhas de produção (70\% e $75 \%$, respectivamente). A empresa ressaltava seu esforço na inclusão e retenção da mão de obra feminina e informava ter aumentado o número de mulheres em posições de comando, fechando o ano de 2013 com 48\% de mulheres em "cargos de liderança" (UNILEVER, 2014). As mulheres representavam 37\% dos que ocupavam cargos em diretoria e $50 \%$ dos que exerciam funções de gerência. Contudo, é preciso esclarecer que "gerência" incluía as funções de coordenação (linha de produção, qualidade, segurança) que conferem posições de "liderança", mas sem poder de decisão e sem autonomia. A Unilever afirmava proporcionar condições iguais de desenvolvimento de carreira para homens e mulheres, e que não havia distinção salarial entre ambos. Eventuais desigualdades de gênero entre cargos de mesmo nível hierárquico estariam associadas ao mérito por performance individual no desempenho de sua função e aquisição de bônus por desempenho. Acrescente-se que o Plano de Sustentabilidade da Unilever 2015/16 não prioriza esses temas.

A Coca-Cola Brasil assegura que uma das mais importantes estratégias voltadas para a gestão de pessoas é o apoio ao crescimento das mulheres dentro da companhia. Em 2012, a empresa criou o grupo Lideranças para o Futuro (LPF), responsável por propor políticas voltadas para o desenvolvimento das "associadas", em especial aquelas em posições de liderança apoiados em quatro pilares: atração, aceleração, retenção e desenvolvimento. Foi criado um programa de coaching de carreira especialmente destinado para mulheres, a adoção do sediamento flexível e a revisão dos valores de reembolso de creche. Segundo o Relatório de Sustentabilidade 2012-2013, apenas 12\% dos 58.600 funcionários próprios da empresa no País eram mulheres; e em 2013 a participação feminina era de $24 \%$ entre os gerentes e de $11 \%$ entre os diretores.

O Relatório de Sustentabilidade 2014-2015 da Coca-Cola Brasil informa que havia equilíbrio na participação de homens e mulheres na sede da empresa (estas eram $51 \%$ dos 594 funcionários em 2015), mas desconsidera os funcionários nas fábricas. É reportada a necessidade de elevar a participação feminina nos demais estabelecimentos do sistema Coca-Cola Brasil (que totalizava 69 mil funcionários). Apesar de existir um programa global da companhia para que as mulheres ocupem $50 \%$ das posições de liderança até 2020 , estava ausente do Relatório a informação sobre a baixa participação feminina entre gerentes e diretores no País. Em relação à remuneração de homens e mulheres ocupando cargos de liderança (diretoria, gerência e chefia/supervisão), a informação relativa à sede da empresa diz que não havia desigualdade significativa (as diferenças são muito pequenas) (COCACOLA, 2015).

O Anuário de Responsabilidade Corporativa 2014 da Volkswagen do Brasil não dá atenção especial às questões relacionadas com a diversidade, apresentando apenas algumas informações sobre a distribuição dos funcionários por gênero e afirmando haver uma preocupação com a inclusão de mulheres, que se expressa no aumento de contratações nos últimos anos ( $29 \%$ do total de contratados em 2014 eram mulheres) (VOLKSWAGEN, 2015). Embora a baixa participação feminina seja um aspecto recorrente na indústria automobilística, a modernização das linhas de produção permitiu que um número maior de mulheres pudesse compor o quadro de funcionários. Mesmo assim, em 2014, no conjunto dos 19.682 funcionários da empresa, $94 \%$ eram homens e apenas $6 \%$

14 Revista Estudos Feministas, Florianópolis, 26(1): e41780 
mulheres. Essa porcentagem era menor na categoria funcional denominada "horista" (produção), que apresentava 3,5\% de seu efetivo formado por mulheres. Já na categoria "mensalista" (atividades administrativas), as mulheres representavam $21 \%$, enquanto no corpo de "executivos" (gestores de unidades, diretores e outros especialistas) a participação feminina equivalia a $9 \%$. Entre os 19 trainees que no futuro poderão assumir cargos de comando, 10 eram mulheres e 9 homens. O Anuário não informa a diferença salarial entre homens e mulheres no Grupo Volkswagen no Brasil.

O Relatório Nestlé na Sociedade 2015 tem como foco principal reportar ações de sustentabilidade e de responsabilidade na cadeia produtiva, deixando um espaço bastante tímido para a política de recursos humanos e equidade de gênero. Um terço dos cargos de gerência era ocupado por mulheres, bem como quase um quarto dos cargos da diretoria. Em 2015, as contratações para cargos de gestão contemplaram $42 \%$ de mulheres, ou seja, o aumento da participação feminina nesse âmbito avança lentamente. O Relatório é superficial em relação aos programas de equidade de gênero: adota um discurso que ressalta a importância do tema, mas não demonstra um compromisso concreto com estratégias específicas para a superação de desigualdades de oportunidades e remuneração (NESTLÉ, 2015). De mais positivo, a política de diversidade da Nestlé tem valorizado a equidade de gênero e o respeito às diferenças ( 400 gestores passaram pelo treinamento Preferências Inconscientes, que visa à conscientização do público interno sobre a diversidade cultural e de raça, opção sexual e gênero).

A Petrobras foi considerada em 2013 como a "empresa dos sonhos dos jovens" (CIA DE TALENTOS, 2013) para trabalhar. No Relatório de Sustentabilidade 2014, enfatiza sua política de diversidade e equidade de gênero afirmando respeitar todas as formas de diversidade ou diferenças pessoais, pois seus empregados têm as mesmas oportunidades de desenvolver seus potenciais e não é tolerado qualquer tipo de discriminação, em consonância com o Programa Pró-Equidade de Gênero e Raça do Governo Federal. O Sistema Petrobras contava, em 2014, com 80.908 empregados, 1.746 estagiários e 291.074 trabalhadores terceirizados (empregados de empresas prestadoras de serviço). Desconsiderando as subsidiárias e as operações em outros países, a empresa tinha no Brasil um efetivo de 58.618 funcionários. Nesse conjunto, havia 4.591 mulheres em funções de nível médio (12,5\% do total) e 4.737 mulheres em funções de nível superior $(21 \%$ do total). Entre 2003-2014, a mão de obra feminina mais do que dobrou, tendo alcançado $16 \%$ do efetivo próprio da empresa no País. O crescimento da participação feminina ocorreu inclusive nas áreas de engenharia.

Em 2014, a presidência da Petrobras era exercida por uma mulher. ${ }^{11}$ Ainda assim, é importante registrar que poucas mulheres alcançavam uma posição na diretoria executiva ou no conselho de direção da companhia (7 em 69). As mulheres ocupavam cerca de 1,8 mil cargos de liderança ( $15 \%$ do total). E a diferença entre a remuneração média dos homens e das mulheres vinha diminuindo. Em 2014, considerando os funcionários com nível médio, as mulheres recebiam uma remuneração que correspondia a $85 \%$ da recebida pelos homens; entre os funcionários com nível superior sem função gratificada, as mulheres recebiam uma remuneração $10 \%$ inferior; e no nível superior com função gratificada a proporção correspondia a $93 \%$. Segundo a empresa, o salário-base de todos os cargos é igual para homens e mulheres. Mas há diferença de remuneração na categoria sem função gratificada em razão da predominância masculina em regimes de trabalho diferenciados

1 Graça Foster foi eleita em 2013 pela Forbes a $18^{\circ}$ mulher mais poderosa do planeta (G1, 2013); em 2014, ficou em quarto lugar na lista das 50 mulheres de negócios mais poderosas do mundo da revista Fortune (VEJA, 2014). 
que possuem adicionais específicos. Além disso, o tempo de companhia influencia na remuneração (em média, o efetivo masculino tem mais anos), ajudando a explicar variações entre a remuneração de homens e mulheres desempenhando função similar (PETROBRAS, 2015).

Embora a breve análise dessas oito empresas não permita oferecer conclusões que possam ser generalizadas para o conjunto das corporações que atuam no Brasil, pode-se constatar que em diversos ramos de atividade persiste a dificuldade de inserção feminina, ainda que as empresas líderes venham adotando programas e ações para modificar a "cultura organizacional" (Andrew M. PETTIGREW, 2007) e promover maior equidade de gênero. $\mathrm{E}$, mesmo no caso de companhias onde a participação feminina é crescente nos cargos de liderança, há um estreitamento de oportunidades à medida que aumenta o nível hierárquico e se mantém uma defasagem salarial entre homens e mulheres.

\section{Considerações finais}

Nas últimas décadas, aumentou a participação feminina no emprego formal e o número de mulheres em profissões que exigem um diploma de educação superior. Mas, apesar de parcela das mulheres desfrutar de maior proteção legal e ter conquistado maior autonomia econômica, ainda persistem as desigualdades de gênero no âmbito profissional, as quais se originam na divisão sexual do trabalho (Carina LUPICA, 2015). Embora venha diminuindo lentamente, este problema parece estar longe de ser solucionado no Brasil, sendo necessário fortalecer as instituições e políticas públicas nesse âmbito.

Do ponto de vista da legislação trabalhista, a igualdade de direitos entre homens e mulheres e a proteção à maternidade foram reconhecidas e positivadas na Constituição Federal de 1988. Desde então, vários operadores do Direito e auditores do trabalho têm se esforçado para assegurar a eficácia dos mecanismos de combate à discriminação de gênero. A equidade nesse terreno exige, no entanto, muito mais do que um arcabouço jurídico. Por isso, foram adotadas políticas públicas para adequar as relações laborais às normas legais (esforço ampliado a partir de 2006, com a Agenda Nacional de Trabalho Decente).

As ações afirmativas não pretendem garantir um tratamento igual, e sim os meios para alcançar uma igualdade efetiva. O desafio é suprimir as desigualdades que restringem as oportunidades profissionais das mulheres e que se refletem no processo de seleção, no salário, nas condições de trabalho, na carreira. Para combater esse tipo de discriminação, é imprescindível que haja vontade política para a adoção de programas de ação afirmativa (BARROS, 2010).

A promoção da equidade de gênero no âmbito das empresas depende da adoção de estratégias efetivas no setor privado. As políticas públicas têm um raio de influência limitado e não são capazes de induzir uma proporção equivalente de homens e mulheres exercendo as mesmas funções nas organizações. Mesmo quando um sindicato denuncia a recorrência de diferenças salariais entre homens e mulheres, dificilmente isso gera uma adequação, uma vez que raramente fica caracterizada a discriminação de gênero.

Em geral, as grandes empresas respeitam a legislação de proteção à mulher e costumam ampliar benefícios por meio de acordos coletivos. Contudo, isso não tem sido suficiente para desfazer a divisão sexual do trabalho que vigora nas corporações, nem para garantir equivalência salarial ou igual oportunidade de alcançar posições de comando nessas organizações. O "teto de vidro" continua a se manifestar nos grandes estabelecimentos no País, assim como persiste o hiato salarial entre homens e mulheres, inclusive entre os profissionais com nível educacional superior. Tais diferenças salariais não 
decorrem apenas dos diferenciais de tempo na empresa, sendo relevante frisar que a remuneração está diretamente relacionada com a progressão na carreira dentro da corporação e com a estrutura escalonada dos cargos (subdivisão das funções de liderança), maquiando a diferença de tratamento entre homens e mulheres que se encontram na mesma posição hierárquica. ${ }^{12}$

Mensurar os diferenciais de rendimento e de acesso a posições de comando é apenas um passo inicial quando se pretende discutir a discriminação de gênero (Ciro BIDERMAN; Nadya Araujo GUIMARÃES, 2004). A discriminação sistêmica explica apenas uma parcela dessas diferenças (GUIMARÃES, 2002). Também é importante esclarecer que uma redução do hiato salarial entre homens e mulheres nem sempre decorre de menor discriminação (Maria Cristina Fábio CACCIAMALI; Fábio TATEI; Jackson William ROSALINO, 2009). Por isso, a análise de dados empíricos agregados deve ser complementada pelo exame de situações particulares.

Embora uma pequena amostra de empresas líderes em alguns ramos de atividade não possa ser considerada representativa do conjunto, parece evidente que há um descompasso entre o discurso enfático contido nos relatórios de sustentabilidade (termo que substituiu a "responsabilidade social empresarial") e os resultados obtidos na promoção da equidade. Chama atenção a proporção muito maior de homens em cargos de liderança (em especial nas diretorias e conselhos de administração) mesmo em multinacionais ou em empresas estatais que poderiam servir de exemplo.

Certamente, é muito positivo que grandes corporações reconheçam a importância de promover a equidade de gênero em suas equipes de trabalho, fazendo entender que está em andamento uma mudança na cultura organizacional. Em todos os casos selecionados há iniciativas interessantes nesse sentido. No entanto, os compromissos assumidos estão longe de produzir resultados satisfatórios. Não se pode dizer que tais programas sejam falaciosos, sendo mais prudente afirmar que os avanços nesse terreno são necessariamente lentos (e deveriam estar alinhados com a estratégia de longo prazo das empresas). Por outro lado, embora vários ramos de atividade tenham sido historicamente dominados por homens, essa não é uma justificativa plausível para a persistência do "teto de vidro".

Para serem eficazes, os programas corporativos de empoderamento das mulheres devem conter ações voltadas para a conciliação entre vida profissional e vida familiar que possibilitem melhores condições para que mais mulheres possam se capacitar para assumir funções de liderança. Essa mudança cultural no interior das empresas não pode ser imposta diretamente pelo Estado, mas, ironicamente, surge como necessidade da competição econômica: programas destinados a atrair e manter mulheres altamente qualificadas são armas na disputa por profissionais de talento, essenciais na estratégia de concorrência em mercados emergentes (Sylvia Ann HEWLETT; Ripa RASHID, 2011).

Enfim, é crucial que grandes empresas se disponham a eliminar por completo os traços de discriminação de gênero que persistem contaminando as relações de trabalho, ainda que esse processo seja bastante gradual e demorado. Ressalte-se que a promoção da igualdade de oportunidades para o desenvolvimento da carreira profissional no âmbito corporativo não implica uma redução da elevada desigualdade de rendimento existente nessas organizações, problema que também deve ser enfrentado.

\footnotetext{
${ }^{12}$ As grandes empresas adotam um escalonamento para cargos de gerência e coordenação com subdivisão em níveis (A, B, C) que têm remunerações distintas. Embora algumas empresas reportem que têm grande número de mulheres gerentes, estas geralmente ocupam a posição $C$, de menor salário, e levam muito mais tempo que os homens para alcançarem (quando alcançam) a posição A. É uma forma de discriminação escamoteada, que perpetua um ambiente corporativo androcêntrico.
} 


\section{Referências}

AGENDA Nacional de Trabalho Decente. Brasília, 2006. Disponível em: http://www.ilo.org/ wcmsp5/groups/public/-americas/_ro-lima/_ilo-brasilia/documents/publication/ wcms_226229.pdf.

BANCO DO BRASIL. Relatório Anual 2015. Brasília: Banco do Brasil, 2015. Disponível em: http:/ /www.bb.com.br/docs/pub/siteEsp/uds/dwn/BBRA15.pdf.

BARBOSA, Daniela; MELO, Luísa. "As 100 empresas de melhor reputação no Brasil em 2014". Exame, 04/06/2014. Disponível em: https://exame.abril.com.br/negocios/100-empresascom-a-melhor-reputacao-do-brasil/.

BARROS, Alice Monteiro de. A mulher e o direito do trabalho. São Paulo: LTr, 1995.

BARROS, Alice Monteiro de. "Discriminação no emprego por motivo de sexo". In: RENAULT, Luiz Otávio Linhares; VIANA, Márcio Túlio; CANTELLI, Paula Oliveira (Coords.). Discriminação. 2.ed. São Paulo: LTr, 2010.

BIDERMAN, Ciro; GUIMARÃES, Nadya Araujo. "Na ante-sala da discriminação: o preço dos atributos de sexo e cor no Brasil (1989-1999)". Revista Estudos Feministas, Florianópolis, v. 12, n. 2, p. 177-200, 2004.

BLOFIELD, Merike; MARTíNEZ, Juliana. "Trabajo, familia y cambios en la política pública en América Latina: equidad, maternalismo y corresponsabilidad”. Revista Cepal, n. 114, p. 107-125, 2014.

BNDES (Banco Nacional de Desenvolvimento Econômico e Social). Circular n. 11/2010. Rio de Janeiro: BNDES, mar. 2010.

BOBBIO, Norberto. A era dos direitos. Rio de Janeiro: Elsevier, 2004.

BRASIL. Constituição da República Federativa do Brasil, 05/10/1988. Disponível em: http:// www2.camara.leg.br/legin/fed/consti/1988/constituicao-1988-5-outubro-1988-322142publicacaooriginal-1-pl.html.

BRUSCHINI, Cristina. "Gênero e trabalho no Brasil: novas conquistas ou persistência da discriminação?". In: ROCHA, Maria Isabel Baltar da (Org.). Trabalho e gênero: mudanças, permanências e desafios. São Paulo: Editora 34, 2000. p. 13-58.

CACCIAMALI, Maria Cristina; TATEI, Fábio; ROSALINO, Jackson William. "Estreitamento dos diferenciais de salários e aumento do grau de discriminação: limites da mensuração padrão?". Planejamento e Políticas Públicas, n. 33, p. 195-222, 2009.

CALIL, Léa Elisa Silingowsch. História do direito do trabalho da mulher: aspectos históricosociológicos do início da república ao final deste século. São Paulo: LTr, 2000.

CIA de talentos. Empresa dos sonhos dos jovens 2013. Brasil, 2013. Disponível em: http:// www.ciadetalentos.com.br/esj/pdf/br/brasil2013 pt.pdf.

COCA-COLA. Relatório de Sustentabilidade 2014-2015. Rio de Janeiro: Coca-Cola Brasil, 2015. Disponível em: https://www.cocacolabrasil.com.br/content/dam/journey/br/pt/ private/pdfs/relatorio-de-sustentabilidade-coca-cola-brasil-2014-15.pdf.

G1. "Graça Foster é a mais poderosa do Brasil nos negócios na lista da Forbes". G1, Economia, 30/05/2013. Disponível em: http://gl.globo.com/economia/negocios/noticia/2013/05/ graca-forbes-e-mais-poderosa-do-brasil-nos-negocios-na-lista-da-forbes. html.

GUIA Você S.A. 2015: as melhores empresas para você trabalhar. São Paulo: Editora Abril; Fundação Instituto de Administração (FIA), 2015.

GUIMARÃES, Nadya Araujo. "Os desafios da equidade: reestruturação e desigualdades de gênero e raça no Brasil". Cadernos Pagu, n. 17-18, p. 237-266, 2002.

HIRATA, Helena. "Flexibilidade, trabalho e gênero". In: HIRATA, Helena Sumiko; SEGNINI, Liliana Rolfsen Petrilli (Orgs.). Organização, trabalho e gênero. São Paulo: SENAC, 2007.

HIRATA, Helena; KERGOAT, Danièle. "Novas configurações da divisão sexual do trabalho". Cadernos de Pesquisa, v. 37, n. 132, p. 595-609, 2007.

18 Revista Estudos Feministas, Florianópolis, 26(1): e41780 
HEWLETT, Sylvia Ann; RASHID, Ripa. Winning the war for talent in emerging markets: why women are the solution. Boston: Harvard Business Review Press, 2011.

IBGE (Instituto Brasileiro de Geografia e Estatística). Estatísticas do cadastro central de empresas 2010. Rio de Janeiro: IBGE, 2012.

IBOPE. Leitores da Seleções elegem Nestlé a marca mais confiável do Brasil, 01/09/2015. Disponível em: http://www.ibope.com.br/pt-br/noticias/Paginas/Leitores-da-Selecoeselegem-Nestle-a-marca-mais-confiavel-do-Brasil.aspx.

IBOPE INTELIGÊNCIA. "Marcas de confiança 2015". Revista Seleções, 2015. Disponível em: http://mais.selecoes.com.br/marcas 2015a/valor.html.

INSTITUTO ETHOS. Indicadores Ethos de responsabilidade social empresarial. São Paulo: Ethos, 2007.

INSTITUTO ETHOS. Perfil social, racial e de gênero das 500 maiores empresas do Brasil e suas ações afirmativas. São Paulo: Ełhos, 2015.

LAVINAS, Lena. "Aumentando a competitividade das mulheres no mercado de trabalho". Revista Estudos Feministas, v. 4, n. 1, p. 171-182, 1996.

LEITE, Marcia de Paula; SALAS, Carlos. "Trabalho e desigualdades sob um novo modelo de desenvolvimento". Tempo Social, USP, v. 26, n. 1, p. 87-100, 2014.

LEONE, Eugenia Troncoso. "O avanço das mulheres na expansão do mercado de trabalho após 2003". Carta Social e do Trabalho, Cesit, n. 29, p. 2-21, 2015.

LEONE, Eugenia Troncoso; TEIXEIRA, Marilane Oliveira. "As mulheres no mercado de trabalho e na organização sindical". Carta Social e do Trabalho, Cesit, n. 21, p. 2-22, 2013.

LOPES, Cristiane Maria Sbalqueiro. "Direito do trabalho da mulher: da proteção à promoção". Cadernos Pagu, n. 26, p. 405-430, 2006.

LUPICA, Carina. "Instituciones laborales y políticas de empleo: avances estratégicos y desafíos pendientes para la autonomía económica de las mujeres". Cepal-Repositorio Digital. Chile: Cepal, 2015. (Serie Asunto de Género, n. 125)

MACHADO, Lia Zanotta. "Perspectivas em confronto: relações de gênero ou patriarcado contemporâneo?". Brasília: UnB, 2000. (Série Antropologia n. 284)

MAGAZINE LUIZA. Relatório Anual e de Sustentabilidade 2015. São Paulo: Magazine Luiza, 2015. Disponível em: https://ri.magazineluiza.com.br/Show/Relatorio-Anual? =mZoQ eKZUHLnTW8oeLFXC4Q==.

MARTINS, Sergio Pinto. Convenções da OIT. São Paulo: Atlas, 2009.

NATURA. Relatório Anual Natura 2015. Caderno de indicadores. São Paulo: Natura, 2015. Disponível em: http://www.natura.com.br/sites/default/files/ra2015_cadernoindicadores_ natura.pdf.

NESTLÉ. Relatório Nestlé na sociedade 2015: criação de valor compartilhado. São Paulo: Nestlé Brasil, 2015. Disponível em: https://www.nestle.com.br/docs/default-source/defaultdocument-library/nestle-rs2015.pdf.

NEVES, Magda de A. "Reestruturação produtiva, qualificação e relações de gênero". In: ROCHA, Maria Isabel Baltar da (Org.). Trabalho e gênero: mudanças, permanências e desafios. São Paulo: Editora 34, 2000.

NOVAIS, Denise Pasello Valente. Discriminação da mulher e Direito do Trabalho: da proteção à promoção da igualdade. São Paulo: LTr, 2005.

OBSERVATÓRIO Social. "A mulher no mercado de trabalho", Observatório Nacional em Revista, n. 5, mar. 2004.

PETTIGREW, Andrew M. "A cultura das organizações é administrável?". In: FLEURY, Maria Tereza Leme; FISCHER, Rosa Maria (Orgs.). Cultura e poder nas organizações. São Paulo: Atlas, 2007. 
PETROBRAS. Relatório de Sustentabilidade 2014. Rio de Janeiro: Petrobras, 2015. Disponível em: http://www.petrobras.com.br/pt/sociedade-e-meio-ambiente/relatorio-desustentabilidade/.

PINTO, Anacleto Laurino; RIBEIRO, Maisa de Souza."Balanço social: avaliação de informações fornecidas por empresas industriais situadas no estado de Santa Catarina". Revista Contabilidade \& Finanças, São Paulo, v. 15, n. 36, 2004.

PRONI, Marcelo Weishaupt; LEONE, Eugenia Troncoso. "Desigualdades de gênero e raça no mercado de trabalho brasileiro". In: KREIN, José Dari et al. (Orgs.). Regulação do trabalho e instituições públicas. São Paulo: Fundação Perseu Abramo, 2013. v.2.

PRONI, Thaíssa Tamarindo da Rocha Weishaupt. Proteção constitucional à maternidade no Brasil: um caso de expansão da garantia legal. São Paulo: LTr, 2013.

SEBRAE (Serviço Brasileiro de Apoio às Micro e Pequenas Empresas) (Org.). Anuário do trabalho na micro e pequena empresa 2013. 6. ed. Brasília-DF: DIEESE, 2013.

SECCHES, Paulo. "Percepções mudam. Posições também. As empresas mais admiradas no Brasil", Carta Capital, 26/10/2015. Disponível em: https://www.cartacapital.com.br/maisadmiradas/percepcoes-mudam-posicoes-tambem-4725.html.

SGARBIERI, Astrid Nilsson. "Representações do gênero feminino na mídia impressa". Estudos Linguísticos, Campinas, v. XXXV, p. 386-371, 2006.

SILVEIRA, Mauro. "GPTW 2015: as melhores empresas para trabalhar". Época, 17/08/2015. Disponível em: http://epoca.globo.com/vida/vida-util/carreira/noticia/2015/08/gptw2015-melhores-empresas-para-trabalhar.html.

STEIL, Andrea Valéria. "Organizações, gênero e posição hierárquica - compreendendo o fenômeno do teto de vidro". Revista de Administração, v. 32, n. 3, p. 62-69, 1997.

TOP Employers reconhece as excelentes práticas de RH das principais empresas do Brasil. UOL Economia, São Paulo, 10/03/2015. Disponível em: https://economia.uol.com.br/ noticias/pr-newswire/2015/03/10/top-employers-reconhece-as-excelentes-praticas-de-rhdas-principais-empresas-do-brasil.htm.

UNILEVER. Relatório de Sustentabilidade 2013. São Paulo: Unilever Brasil, 2014. Disponível em: https://www.unilever.com.br/Images/relatorio-de-sustentabilidade-2013_tcm 1284461457_1_pt.pdf.

VEJA. "Fortune: Graça Foster é a 4a mulher mais poderosa do mundo". Veja, Economia, 07/ 02/2014. Disponível em: http://veja.abril.com.br/economia/fortune-graca-foster-e-a-4amulher-mais-poderosa-do-mundo/.

VOLKSWAGEN. Anuário de responsabilidade corporativa 2014. São Bernardo do Campo: Volkswagen do Brasil, 2015. Disponível em: http://static.globalreporting.org/report-pdfs/ 2015/a3a86e31 e3739ef46460a3308a7b3f89.pdf.

[Recebido em 10/1 1/2015, reapresentado em 10/12/2016 e aprovado em 13/04/2017]

\section{Gender Discrimination in Large Companies in Brazil}

Abstract: The problem of gender discrimination at work is also evident in large companies. In general, men receive higher wages than women, even performing the same function. It is more difficult for women to reach high command position because of the "glass ceiling". The fight against gender discrimination fostered by developments in labour law and public policy is essential to value the female workforce, but is unable to eliminate the differences in terms of career advancement and remuneration for men and women, even in enterprise market leaders. Initiatives to promote gender equity in the corporate world, included in corporate social 
responsibility programs, produce slow progress and require a change of organizational culture. Keywords: Gender discrimination; Labour law; Glass ceiling

Thaíssa Tamarindo da Rocha Weishaupt Proni (thaissa.rocha@gmail.com) é advogada, mestre em Direito do Trabalho pela USP e doutoranda em Ciências Sociais pelo IFCH-UNICAMP. Áreas de pesquisa: trabalho, política e sociedade.

Marcelo Weishaupt Proni (mwproni@eco.unicamp.br) é graduado em Economia pela Unicamp, mestre em Ciências Econômicas, doutor em Educação Física pela Unicamp e livre docente em Economia do Trabalho. É pesquisador do Centro de Estudos Sindicais e Economia do Trabalho (Cesit). É professor do Instituto de Economia da Universidade Estadual de Campinas, tendo sido diretor associado entre outubro de 2011 e outubro de 2015. 